\title{
CHANGE IN TRANSVERSE SLOPE OF WATER SURFACE AT RIVER BEND: A NUMERICAL STUDY
}

\author{
Priyata Rahman ${ }^{1}$ and Md. Shahjahan $\mathrm{Ali}^{* 2}$ \\ ${ }^{1}$ Former Student, ${ }^{2}$ Professor \\ Department of Civil Engineering, Khulna University of Engineering \& Technology, Bangladesh
}

Received: 14 March 2021

Accepted: 24 June 2021

\begin{abstract}
Generation of secondary current in a meandering river flow due to the centrifugal force acting on the bend is three dimensional (3D) in nature. But in case of practical problems like alluvial geomorphic processes, 3D models are not proved to be efficient. Hence, two dimensional (2D) models are generally adopted for such problems. This study offers a presentation of numerical simulation results for turbulent flows around bends of a meandering channel for different meander angles. $2 \mathrm{D}$ models were built by the use of iRIC Nays $2 \mathrm{DH}$ solver for flow simulation of $45^{\circ}, 90^{\circ}$, $135^{\circ}, 180^{\circ}$ meandering bends with varying widths of $0.15 \mathrm{~m}, 0.25 \mathrm{~m}, 0.75 \mathrm{~m}, 1.00 \mathrm{~m}, 1.25 \mathrm{~m}$ and $1.50 \mathrm{~m}$ considering constant Froude number with constant meandering length $\left(M_{L} / W\right)$ and constant radius of curvature $(R / W)$. Zero equation model was used as turbulence closure with finite differential advections as upwind scheme. The flow behavior has been studied at the apex and cross over portions of bends. From the simulation, the velocity at outer bank was found to be lower than that of the inner bank while the water surface elevation was found to be higher than that of the inner bank. Increase in transverse slope of water surface at bend was observed for increasing meander angles, Froude numbers and decreasing channel widths.
\end{abstract}

Keywords: Meandering River, Two-dimensional Flow, Turbulent Flow, Simulation, iRIC, Nays2DH.

\section{INTRODUCTION}

Meandering planform in natural rivers are most common in the river morphology. Therefore, the flow simulation of such river has been a popular topic for research in river engineering and water resources engineering field. When water flows along bends, it shows three dimensional (3D) patterns as secondary current is produced due to deviation of flow (Bai et al. 2019; Xu et al. 2017). When flow approaches to bends, water current flows from the convex side towards the concave. This phenomenon is mainly created by the centrifugal forces acting on the water surface. In contrast, the water surface in the outer bank rises and makes the inner bank lower thus balances the centrifugal force acting on water surface. This causes variation in flow rate along different portion of the river. This elevation change between the outer and inner banks creates transverse slope in water surface. The study of such a flow involves three dimensional (3D) hydrodynamic model. But for the practical application like the alluvial geomorphic processes, the 3D model does not provide much efficiency and not cost effective (Kimura et al., 2009; Ali et al., 2017). For this reason, generally two-dimensional (2D) model is adopted to simulate the flow in a meandering river. The study and analysis of flow through meandering channels hold extensive interest in the field of river engineering for the construction of flood retention structures as rivers play a vital role in influencing the environment. Meandering rivers are formed when sediment erosion occurs, comprising an outer concave bank which is followed by deep scour holes and deposition of sediments are executed on an inner convex curve at downstream creating shallow depth. The creation of inner bank is encouraged by the development of vegetation at low flow stages and consequently stabilizing the point bar (the submergence of zone of minimum flow depth). The transport of sediments from the outer bank to the inner bank brings changes in the shape of the river. Thus enhances the creation of meander channels. The continuous migration of meander channels can be a reason of many practical problems such as bank erosion, shifting of center line and boundaries, loss of fertile soil, heterogeneous sediment stratigraphy etc.

In the past, many researchers have taken initiative to explain the flow pattern in a meander by considering different meander angles and discharges with varying geometric conditions. Kim and Choi (2003) performed an experiment to simulate the open channel flows in meandering bend. By considering the finite element method they evaluated the 2D numerical algorithm to complete the simulation. Rozovskii (1961) considered a completely smooth and rough bed of a rectangular channel with $180^{\circ}$ meander bends where the channel width was taken to be $80 \mathrm{~cm}$ and the radius 
of curvature for the $180^{\circ}$ bend was $80 \mathrm{~cm}$ on the centerline. He gave an extensive discussion on the flow mechanism of the meander and explained the generation of secondary current through bends and also interpreted the change of tangential secondary current of flow while traversing a bend. A numerical model in harmony of Rozovskii tests was formed by Leschziner and Rodi (1974) for a $90^{\circ}$ strongly curved bend where the ratio of average radius to width was considered as 1 . In the research, they found the external bank surface slope to be lower than the inner bank surface slope and did not get a linear surface slope along the cross section. De Vriend and Geoldof (1983) constructed a model with $90^{\circ}$ central angle and the surface transversal profile was found to be linear but the calculation of water surface elevation along the upstream and downstream bends were not done. Ali et al. (2014) worked on the flow pattern around a bend in an open channel for different bend angles of $45^{\circ}, 90^{\circ}, 135^{\circ}$ and $180^{\circ}$. The simulation was done by using the iRIC software. Sharply and mildly curved channels were constructed for predicting the simulation of the flow field. The length of the high velocity zone in inner bank and low velocity zone in outer bank along stream-wise direction was found higher for $135^{\circ}$ bend and gradually decreasing with the decrease of bend angle. Ahmadi et al. (2009) worked on a 2D depth-average model for simulating the unsteady flow norms in bends of an open channel. The impression of the secondary flow occurrence was considered in the calculation of dispersion stresses. They also illustrated a good simulation result with improved dispersion terms.

In this study, a 2D software named iRIC Nays2DH is used for the simulation of turbulent flows around bends of a meandering channel for different meander angles. For each bend angle, the simulation was performed with varying widths considering constant Froude number with constant meandering length $\left(\mathrm{M}_{\mathrm{L}} / \mathrm{W}\right)$ and constant radius of curvature $(\mathrm{R} / \mathrm{W})$. The flow behavior has been studied at the apex and cross over portions of bends. From the simulation, change in transverse slope of water surface at a bend has been analyzed for different meander angles, Froude numbers and channel widths.

\section{SIMULATION TECHNIQUE}

In this study the iRIC Nays2DH solver has been used to simulate the flow fields. The iRIC software provides a vast scope for evaluating the flow in a domain such as- transport of sediment, evaluation of bed, two- and threedimensional flow simulation, processing of topographic data, ground-surface-water interrelation, assessment of dwelling, model output visualization, editing tools, mapping, extracting data etc. (iRIC, 2017; Shimizu \& Takebayashi, 2014). This software is made suitable for exploiting the sets of river data from the river reaches. An advantage is that a user can readily use the software as the models are adorned with single graphical user interface and hence there is no need for the user to learn the pre and post processing tools. This approach is made available for the users by supporting all documentation in public domain. Nays2DH comprises an analytical model for the simulation of two-dimensional (2D) horizontal flow, morphological variation of beds and banks of river and transport of sediment. The basic equations used in this model are obtained from the transformation of the basic equations in an orthogonal co-ordinates system (x, y) into a general curvilinear co-ordinate system as follows (Shimizu \& Takebayashi, 2014):

Continuity Equation: $\quad \frac{\partial}{\partial t}\left(\frac{h}{J}\right)+\frac{\partial}{\partial \xi}\left(\frac{h u^{\xi}}{J}\right)+\frac{\partial}{\partial \eta}\left(\frac{h u^{\eta}}{J}\right)=0$

Momentum Equations:

$$
\begin{aligned}
& \frac{\partial u^{\xi}}{\partial t}+u^{\xi} \frac{\partial u^{\xi}}{\partial \xi}+u^{\eta} \frac{\partial u^{\eta}}{\partial \eta}+\alpha_{1} u^{\xi} u^{\xi}+\alpha_{2} u^{\xi} u^{\eta}+\alpha_{3} u^{\eta} u^{\eta}=-g\left[\left(\xi_{x}^{2}+\xi_{y}^{2}\right) \frac{\partial H}{\partial \xi}+\left(\xi_{x} \eta_{x}+\xi_{y} \eta_{y}\right) \frac{\partial H}{\partial \eta}\right]-\left(C_{f}+\right. \\
& \left.\frac{1}{2} C_{D} \alpha_{s} h\right) \frac{u^{\eta}}{h J} \sqrt{\left(\eta_{y} u^{\xi}-\xi_{y} u^{\eta}\right)^{2}+\left(-\eta_{x} u^{\xi}-\xi_{x} u^{\eta}\right)^{2}}+D^{\eta} \\
& \frac{\partial u^{\xi}}{\partial t}+u^{\xi} \frac{\partial u^{\xi}}{\partial \xi}+u^{\eta} \frac{\partial u^{\eta}}{\partial \eta}+\alpha_{4} u^{\xi} u^{\xi}+\alpha_{5} u^{\xi} u^{\eta}+\alpha_{6} u^{\eta} u^{\eta}=-g\left[\left(\eta_{x} \xi_{x}+\eta_{y} \xi_{y}\right) \frac{\partial H}{\partial \xi}+\left(\eta_{x}^{2}+\eta_{y}^{2}\right) \frac{\partial H}{\partial \eta}\right]-\left(C_{f}+\right. \\
& \left.\frac{1}{2} C_{D} \alpha_{s} h\right) \frac{u^{\eta}}{h J} \sqrt{\left(\eta_{y} u^{\xi}-\xi_{y} u^{\eta}\right)^{2}+\left(-\eta_{x} u^{\xi}-\xi_{x} u^{\eta}\right)^{2}}+D^{\eta}
\end{aligned}
$$

where,

$$
\begin{aligned}
& \alpha_{1}=\xi_{x} \frac{\partial^{2} x}{\partial \xi^{2}}+\xi_{y} \frac{\partial^{2} y}{\partial \xi^{2}}, \alpha_{2}=2\left(\xi_{x} \frac{\partial^{2} x}{\partial \xi \partial \eta}+\xi_{y} \frac{\partial^{2} y}{\partial \xi \partial \eta}\right), \alpha_{3}=\xi_{x} \frac{\partial^{2} x}{\partial \eta^{2}}+\xi_{y} \frac{\partial^{2} y}{\partial \eta^{2}} \\
& \alpha_{4}=\eta_{x} \frac{\partial^{2} x}{\partial \xi^{2}}+\eta_{y} \frac{\partial^{2} y}{\partial \xi^{2}}, \alpha_{5}=2\left(\eta_{x} \frac{\partial^{2} x}{\partial \xi \partial \eta}+\eta_{y} \frac{\partial^{2} y}{\partial \xi \partial \eta}\right), \alpha_{6}=\eta_{x} \frac{\partial^{2} x}{\partial \eta^{2}}+\eta_{y} \frac{\partial^{2} y}{\partial \eta^{2}}
\end{aligned}
$$


$D^{\xi}=\left(\xi_{x} \frac{\partial}{\partial \xi}+\eta_{x} \frac{\partial}{\partial \eta}\right)\left[v_{t}\left(\xi_{x} \frac{\partial u^{\xi}}{\partial \xi}+\eta_{x} \frac{\partial u^{\eta}}{\partial \eta}\right)\right]+\left(\xi_{y} \frac{\partial}{\partial \xi}+\eta_{y} \frac{\partial}{\partial \eta}\right)\left[v_{t}\left(\xi_{y} \frac{\partial u^{\xi}}{\partial \xi}+\eta_{y} \frac{\partial u^{\eta}}{\partial \eta}\right)\right]$

$D^{\eta}=\left(\xi_{x} \frac{\partial}{\partial \xi}+\eta_{x} \frac{\partial}{\partial \eta}\right)\left[v_{t}\left(\xi_{x} \frac{\partial u^{\eta}}{\partial \xi}+\eta_{x} \frac{\partial u^{\eta}}{\partial \eta}\right)\right]+\left(\xi_{y} \frac{\partial}{\partial \xi}+\eta_{y} \frac{\partial}{\partial \eta}\right)\left[v_{t}\left(\xi_{y} \frac{\partial u^{\eta}}{\partial \xi}+\eta_{y} \frac{\partial u^{\eta}}{\partial \eta}\right)\right]$

$\xi_{x}=\frac{\partial \xi}{\partial x}, \xi_{y}=\frac{\partial \xi}{\partial y}, \eta_{x}=\frac{\partial \eta}{\partial x} \eta_{y}=\frac{\partial \eta}{\partial y}$

$u^{\xi}=\xi_{x} u+\xi_{y} v, u^{\eta}=\eta_{x} u+\eta_{y} v \mathrm{~b}$

$J=\frac{1}{x_{\xi} y_{\eta}-x_{\eta} y_{\xi}}$

$k-\varepsilon$ model is used for turbulent closure. In the standard $k-\varepsilon$ model, the eddy viscosity co-efficient can be obtained by Eq. (4).

$v_{t}=C_{\mu} \frac{k^{2}}{\epsilon}$

where, $C_{\mu}=$ model constant,

$\mathrm{k}$ and $\epsilon$ are attained by the following equations-

$$
\begin{aligned}
& \frac{\partial k}{\partial t}+u \frac{\partial k}{\partial t}+v \frac{\partial k}{\partial t}=\frac{\partial}{\partial x}\left(\frac{v_{t}}{\sigma_{k}} \frac{\partial k}{\partial x}\right)+\frac{\partial}{\partial y}\left(\frac{v_{t}}{\sigma_{k}} \frac{\partial k}{\partial y}\right)+P_{h}+P_{k v}-\epsilon \\
& \frac{\partial \epsilon}{\partial t}+u \frac{\partial \epsilon}{\partial t}+v \frac{\partial \epsilon}{\partial t}=\frac{\partial}{\partial x}\left(\frac{v_{t}}{\sigma_{\epsilon}} \frac{\partial \epsilon}{\partial x}\right)+\frac{\partial}{\partial y}\left(\frac{v_{t}}{\sigma_{\epsilon}} \frac{\partial \epsilon}{\partial y}\right)+C_{1_{\epsilon}} \frac{\epsilon}{k} P_{h}+P_{\epsilon v}-C_{2_{\epsilon}} \frac{\epsilon^{2}}{k}
\end{aligned}
$$

Table 1: Model constants (after Ali et al., 2012)

\begin{tabular}{cccll}
\hline $\boldsymbol{C}_{\boldsymbol{\mu}}$ & $\boldsymbol{C}_{\mathbf{1}_{\boldsymbol{\epsilon}}}$ & $\boldsymbol{C}_{\mathbf{2}_{\boldsymbol{\epsilon}}}$ & $\boldsymbol{\sigma}_{\boldsymbol{k}}$ & $\boldsymbol{\sigma}_{\boldsymbol{\epsilon}}$ \\
\hline 0.09 & 1.44 & 1.92 & 1.00 & 1.30 \\
\hline
\end{tabular}

Where, $C_{1_{\epsilon}}, C_{2_{\epsilon}}, \sigma_{\boldsymbol{k}}$ and $\sigma_{\epsilon}$ are the model constants having the values given in Table 1 .

The terms $P_{k v}$ and $P_{\epsilon v}$ are obtained by-

$P_{k v}=C_{k} \frac{u_{*}^{3}}{h}=0.33$

$P_{\epsilon v}=C_{k} \frac{u_{*}^{4}}{h^{2}}$

\subsection{NUMERICAL TEST CASES}

The hydraulic parameters for numerical test cases that were adopted in this study for flow simulation are given in Table 2. Figure 1 shows the meander geometry for series $S_{1}$. In the simulation cases, the width of the channel varies from 0.15 to $1.50 \mathrm{~m}$ and meander length varies from 4.5 to $45 \mathrm{~m}$ having a constant meandering length $\mathrm{M}_{\mathrm{L}} / \mathrm{W}=30$ and for a constant radius of curvature $\mathrm{R} / \mathrm{W}=7.5 .56$ numbers of numerical test cases for flow simulations were run within the seven series $\left(S_{1}\right.$ to $\left.S_{7}\right)$ of numerical test cases as shown in Table 3. The simulations were performed for bend angles of $45^{\circ}, 90^{\circ}, 135^{\circ}$ and $180^{\circ}$ as well as for Froude numbers of 0.25 and 0.50 .

\begin{tabular}{|c|c|c|c|c|c|c|}
\hline Series No. & $\begin{array}{c}\text { Width of } \\
\text { Channel, } \\
W \\
(\mathrm{~m})\end{array}$ & $\begin{array}{c}\text { Meander } \\
\text { Length, } \\
M_{L} \\
\text { (m) }\end{array}$ & $\frac{M_{L}}{W}$ & $\begin{array}{c}\text { Meander Belt } \\
\text { (m) }\end{array}$ & $\begin{array}{c}\text { Length of } \\
\text { Channel } \\
\text { (m) }\end{array}$ & $\begin{array}{c}\text { Radius of } \\
\text { Curvature } R, \\
\text { (m) }\end{array}$ \\
\hline$S_{1}$ & 0.15 & 4.5 & 30 & 2.41 & 12 & 1.13 \\
\hline$S_{2}$ & 0.25 & 7.5 & 30 & 4.01 & 20 & 1.88 \\
\hline$S_{3}$ & 0.50 & 15.0 & 30 & 8.00 & 40 & 3.75 \\
\hline$S_{4}$ & 0.75 & 22.5 & 30 & 12.01 & 60 & 5.63 \\
\hline$S_{5}$ & 1.00 & 30.0 & 30 & 16.00 & 80 & 7.50 \\
\hline$S_{6}$ & 1.25 & 37.5 & 30 & 20.01 & 100 & 9.38 \\
\hline$S_{7}$ & 1.50 & 45.0 & 30 & 24.00 & 120 & 11.25 \\
\hline
\end{tabular}

Table 2: Meander parameters. 


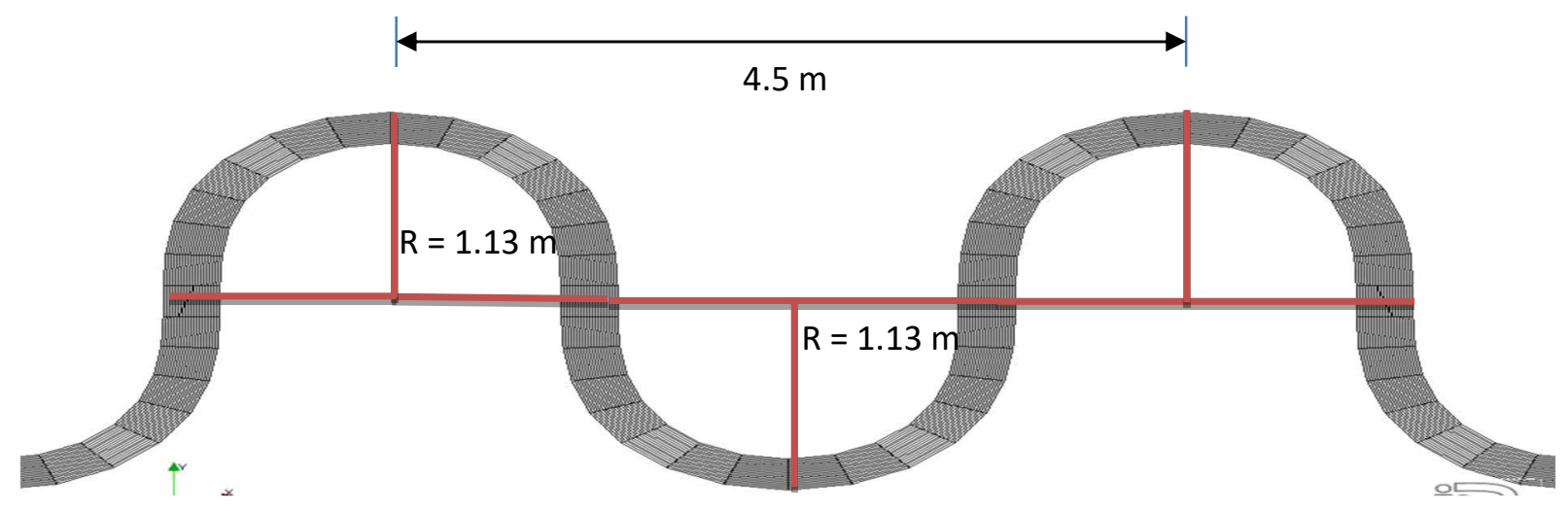

Figure 1: Meander geometry for series $S_{1}$.

Table 3: Hydraulic parameters for numerical test cases.

\begin{tabular}{cccccc}
\hline $\begin{array}{c}\text { Series } \\
\text { No. }\end{array}$ & Case No. & Bend Angle & Fr & $\begin{array}{c}\text { Width of } \\
\text { Channel (m) }\end{array}$ & $\begin{array}{c}\text { Discharge, } \mathbf{Q} \\
\left(\mathbf{m}^{\mathbf{3}} / \mathbf{s}\right)\end{array}$ \\
\hline \multirow{2}{*}{$\boldsymbol{S}_{\mathbf{1}}$} & $S_{1} C_{1} R_{1} \sim S_{1} C_{1} R_{4}$ & $45^{\circ}, 90^{\circ}, 135^{\circ}, 180^{\circ}$ & 0.25 & 0.15 & 0.05459 \\
& $S_{1} C_{2} R_{1} \sim S_{1} C_{2} R_{4}$ & $45^{\circ}, 90^{\circ}, 135^{\circ}, 180^{\circ}$ & 0.50 & 0.15 & 0.10918 \\
$\boldsymbol{S}_{\mathbf{2}}$ & $S_{2} C_{1} R_{1} \sim S_{2} C_{1} R_{4}$ & $45^{\circ}, 90^{\circ}, 135^{\circ}, 180^{\circ}$ & 0.25 & 0.25 & 0.09098 \\
& $S_{2} C_{2} R_{1} \sim S_{2} C_{2} R_{4}$ & $45^{\circ}, 90^{\circ}, 135^{\circ}, 180^{\circ}$ & 0.50 & 0.25 & 0.18195 \\
$\boldsymbol{S}_{3}$ & $S_{3} C_{1} R_{1} \sim S_{3} C_{1} R_{4}$ & $45^{\circ}, 90^{\circ}, 135^{\circ}, 180^{\circ}$ & 0.25 & 0.50 & 0.18196 \\
& $S_{3} C_{2} R_{1} \sim S_{3} C_{2} R_{4}$ & $45^{\circ}, 90^{\circ}, 135^{\circ}, 180^{\circ}$ & 0.50 & 0.50 & 0.36390 \\
$\boldsymbol{S}_{\mathbf{4}}$ & $S_{4} C_{1} R_{1} \sim S_{4} C_{1} R_{4}$ & $45^{\circ}, 90^{\circ}, 135^{\circ}, 180^{\circ}$ & 0.25 & 0.75 & 0.27294 \\
& $S_{4} C_{2} R_{1} \sim S_{4} C_{2} R_{4}$ & $45^{\circ}, 90^{\circ}, 135^{\circ}, 180^{\circ}$ & 0.50 & 0.75 & 0.54585 \\
$\boldsymbol{S}_{5}$ & $S_{5} C_{1} R_{1} \sim S_{5} C_{1} R_{4}$ & $45^{\circ}, 90^{\circ}, 135^{\circ}, 180^{\circ}$ & 0.25 & 1.00 & 0.36392 \\
& $S_{5} C_{2} R_{1} \sim S_{5} C_{2} R_{4}$ & $45^{\circ}, 90^{\circ}, 135^{\circ}, 180^{\circ}$ & 0.50 & 1.00 & 0.72780 \\
$\boldsymbol{S}_{\mathbf{6}}$ & $S_{6} C_{1} R_{1} \sim S_{6} C_{1} R_{4}$ & $45^{\circ}, 90^{\circ}, 135^{\circ}, 180^{\circ}$ & 0.25 & 1.25 & 0.45490 \\
& $S_{6} C_{2} R_{1} \sim S_{6} C_{2} R_{4}$ & $45^{\circ}, 90^{\circ}, 135^{\circ}, 180^{\circ}$ & 0.50 & 1.25 & 0.90975 \\
$\boldsymbol{S}_{\mathbf{7}}$ & $S_{7} C_{1} R_{1} \sim S_{7} C_{1} R_{4}$ & $45^{\circ}, 90^{\circ}, 135^{\circ}, 180^{\circ}$ & 0.25 & 1.50 & 0.54588 \\
& $S_{7} C_{2} R_{1} \sim S_{7} C_{2} R_{4}$ & $45^{\circ}, 90^{\circ}, 135^{\circ}, 180^{\circ}$ & 0.50 & 1.50 & 1.09170 \\
\hline
\end{tabular}

In Table 3, $R_{1}, R_{2}, R_{3}$ and $R_{4}$ represents simulation run for $45^{\circ}, 90^{\circ}, 135^{\circ}$ and $180^{\circ}$ bend angles of meanders, respectively. $S_{1}, S_{2}, S_{3}, S_{4}, S_{5}, S_{6}$ and $S_{7}$ stands for the series numbers having channel widths of $0.15 \mathrm{~m}, 0.25 \mathrm{~m}$, $0.50 \mathrm{~m}, 0.75 \mathrm{~m}, 1.00 \mathrm{~m}, 1.25 \mathrm{~m}$ and $1.50 \mathrm{~m}$, respectively. $C_{1}$ and $C_{2}$ are the cases of simulation for Froude numbers of 0.25 and 0.50 .

\section{RESULTS AND DISCUSSION}

The meander length of models varied with channel widths, as the ratio of meander length to width of the channel were taken to be a constant value of 30. Number of grids in the longitudinal and transverse direction was 161 and 21 respectively. At the sidewall locations, the logarithmic law was encountered in the numerical solution. Boundary conditions were set up by inserting a constant discharge at upstream and a constant depth at the downstream end. Seven sections of 1-1, 2-2, 3-3, 4-4, 5-5, 6-6 and 7-7 were considered at bend and cross-over portions (as illustrated in Figure 2) to study the flow depth and change in surface slope. 


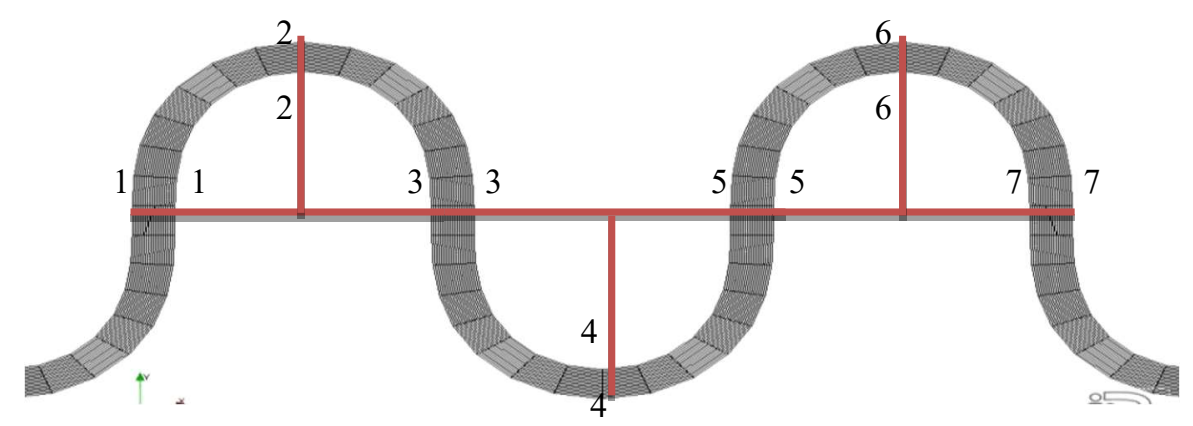

Figure 2: Numerical grid with observation sections

\subsection{Simulated Flow Profiles}

Figure 3 shows that the value of depth was high for the outer concave end in comparison with the inner convex end and the center of the channel. Thus it developed a transverse water surface slope. From the velocity vectors in Figure 3 , it is evident that the velocity vectors were high in inner convex end and low in outer concave end. The value of water surface elevation was found higher for higher Froude number (0.50) than lower Froude number $(0.25)$.

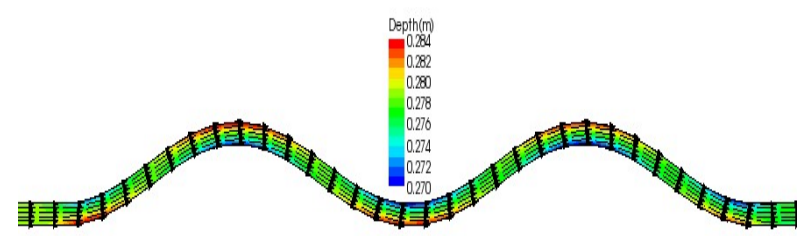

(a) Case $S_{1} C_{1} R_{1}$

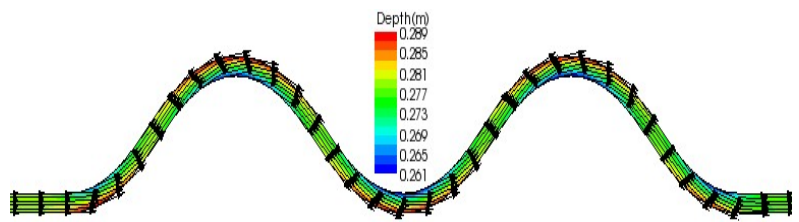

(c) Case $S_{1} C_{1} R_{2}$

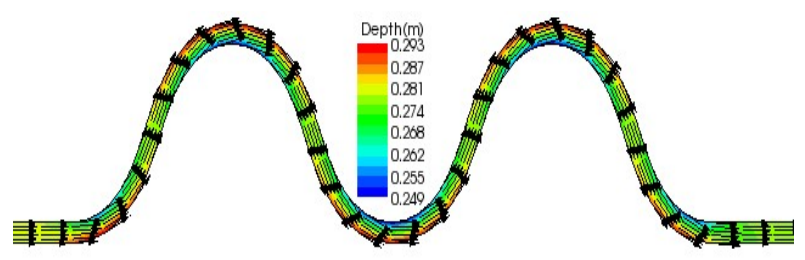

(e) Case $S_{1} C_{1} R_{3}$

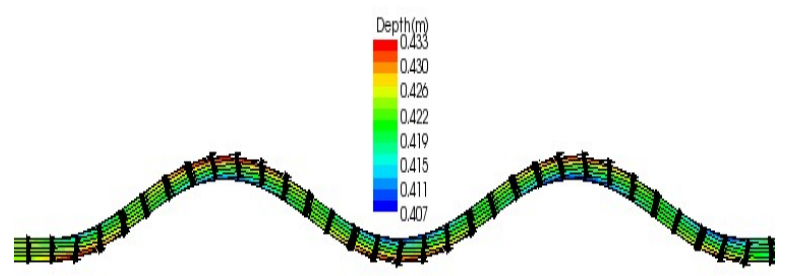

(b) Case $S_{1} C_{2} R_{1}$

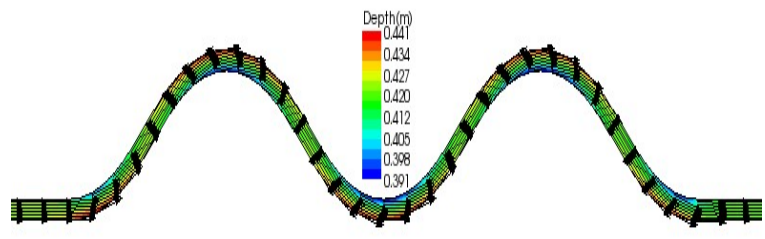

(d) Case $S_{1} C_{2} R_{2}$

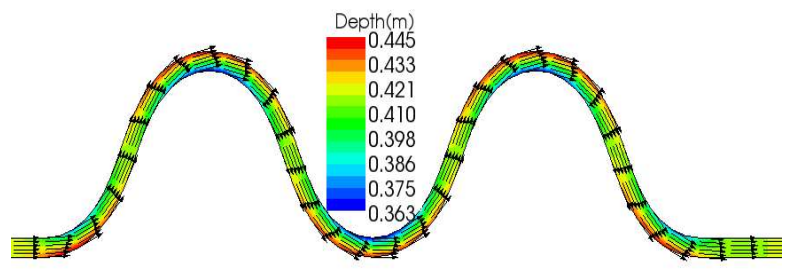

(f) Case $S_{1} C_{2} R_{3}$ 


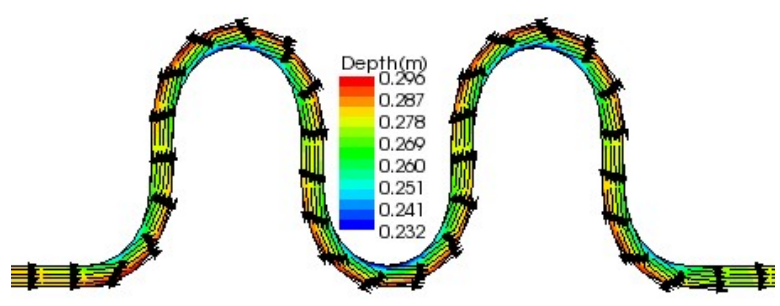

(g) Case $S_{1} C_{1} R_{4}$

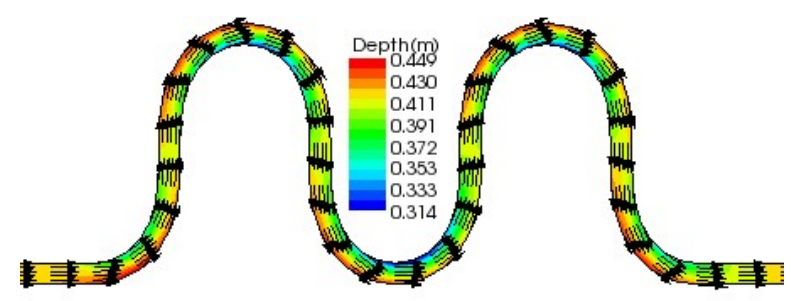

(h) Case $S_{1} C_{2} R_{4}$

Figure 3: Simulated velocity vectors superimposed with depth contour for cases $S_{1} C_{1} R_{1} \sim S_{1} C_{1} R_{4}$ and $S_{1} C_{2} R_{1} \sim S_{1} C_{2} R_{4}$.

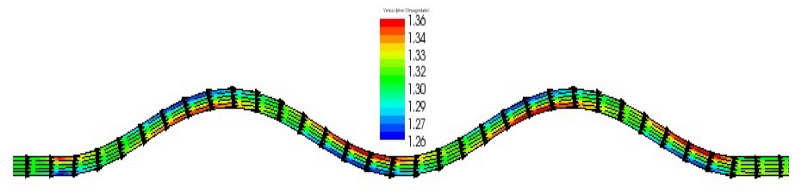

(a) Case $S_{1} C_{1} R_{1}$

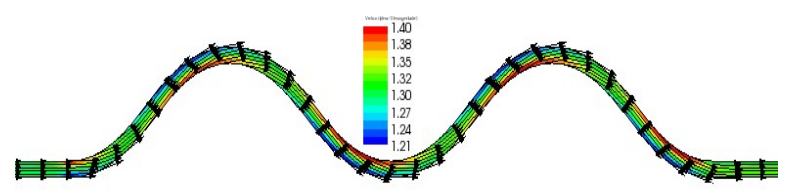

(c) Case $S_{1} C_{1} R_{2}$

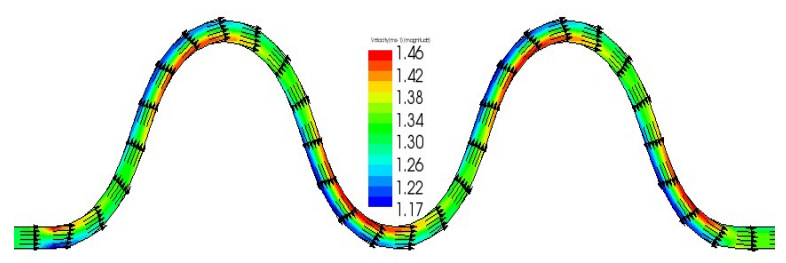

(e) Case $S_{1} C_{1} R_{3}$

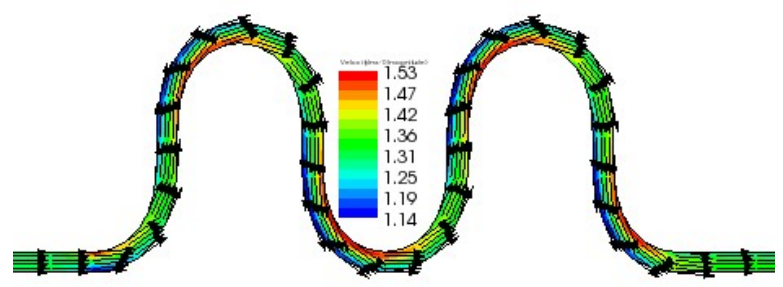

(g) Case $S_{1} C_{1} R_{4}$

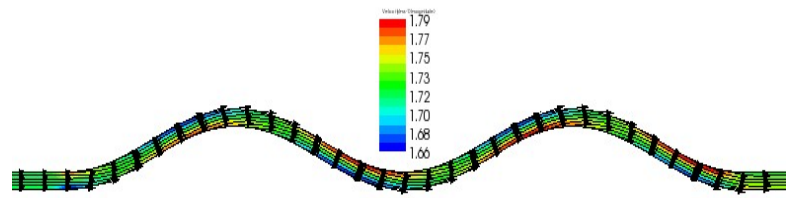

(b) Case $S_{1} C_{2} R_{1}$

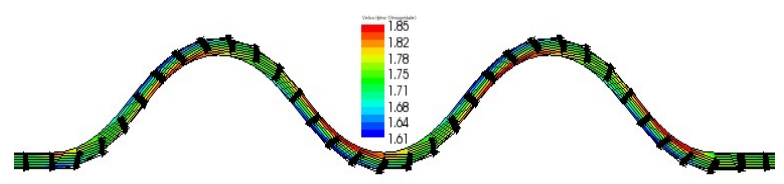

(d) Case $S_{1} C_{2} R_{2}$

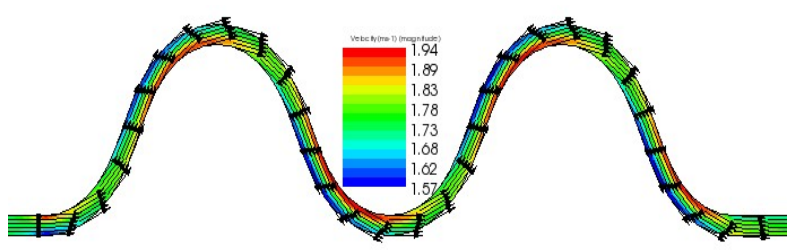

(f) Case $S_{1} C_{2} R_{3}$

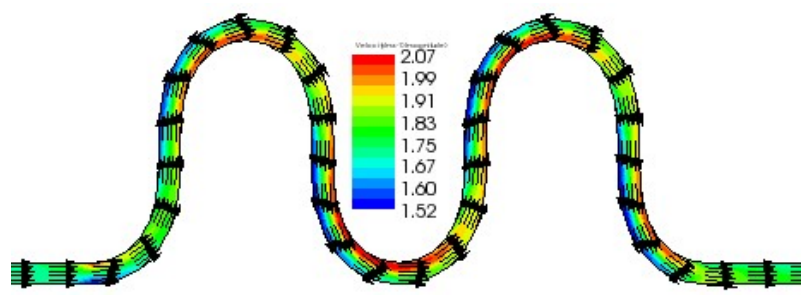

(h) Case $S_{1} C_{2} R_{4}$

Figure 4: Simulated velocity vectors superimposed with velocity contour for cases $\left(S_{1} C_{1} R_{1} \sim S_{1} C_{1} R_{4}\right)$ and $\left(S_{1} C_{2} R_{1} \sim S_{1} C_{2} R_{4}\right)$. 
Figure 4 shows that the velocity in the outer bank is lower while the velocity at the inner bank is higher. The velocity at the center of the channel is found higher than that of the velocity magnitude at the outer bank. From the velocity vectors in Figure 4, it is also evident that the velocities are high in inner convex end and low in outer concave end. The value of velocity magnitude is found higher for higher Froude number $(\mathrm{Fr}=0.50)$ compared to lower value of $\operatorname{Fr}(\mathrm{Fr}=0.25)$.

\subsection{Transverse Slope in Water Surface}

From Figure 5, it is found that the transverse slope of water surface at the cross over sections of a meander is lower than that of the apex points. The transverse slope is found to decrease with the increase of width of the channel. It is found out that the change in transverse slope of water surface varied rapidly for channel widths between 0.15 to 0.75 $\mathrm{m}$, while the change in transverse slope was gradual for width of channel greater than $0.75 \mathrm{~m}$.

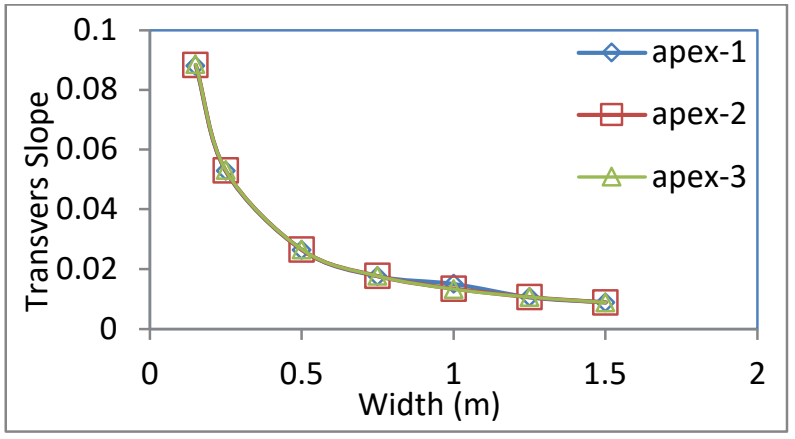

(a) $\left(S_{1} C_{1} R_{1} \sim S_{7} C_{1} R_{1}\right)$.

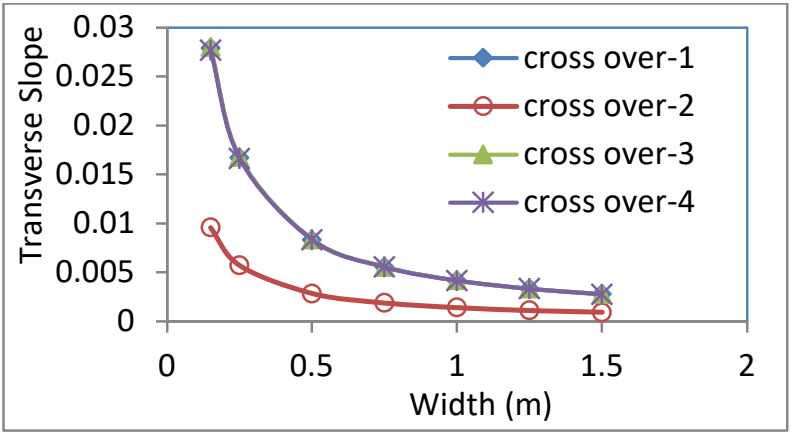

(b) $\left(S_{1} C_{1} R_{1} \sim S_{7} C_{1} R_{1}\right)$

Figure 5: Transverse slope at apex points and cross-over points for different values of widths for Froude number $\mathrm{Fr}=0.25$ having constant meandering length $\left(\mathrm{M}_{\mathrm{L}} / \mathrm{W}=30\right)$ and constant radius of curvature $(\mathrm{R} / \mathrm{W}=7.5)$

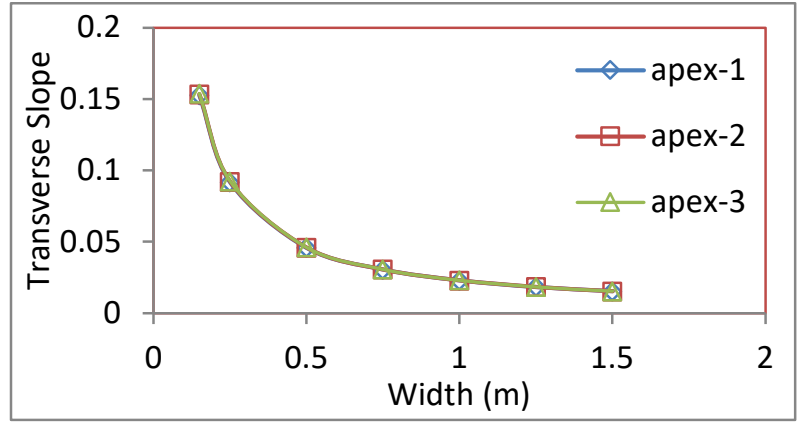

(a) $\left(S_{1} C_{2} R_{1} \sim S_{7} C_{2} R_{1}\right)$.

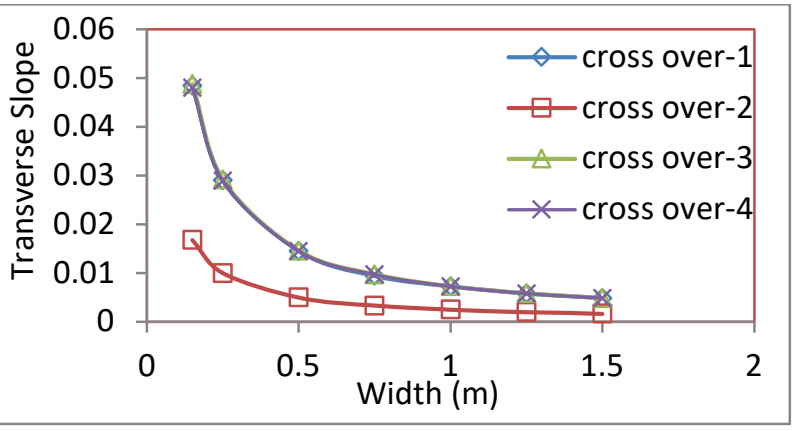

(b) $\left(S_{1} C_{2} R_{1} \sim S_{7} C_{2} R_{1}\right)$.

Figure 6: Transverse slope at apex points and cross-over points for different values of widths for Froude number $\mathrm{Fr}=0.50$ having constant meandering length $\left(\mathrm{M}_{\mathrm{L}} / \mathrm{W}=30\right)$ and constant radius of curvature $(\mathrm{R} / \mathrm{W}=7.5)$

Figure 6 shows that the transverse slope of water surface at the cross over points of a bend is lower than that of the apex points. The transverse slope was found to decrease with the increase of width of the channel. It is observed that the change in transverse slope of water surface varies rapidly for channel widths between $0.15-0.75 \mathrm{~m}$ while the change in transverse slope was gradual for width of channel greater than $0.75 \mathrm{~m}$. This is probably due to the change in the structure of secondary currents with the depth-width ratios of the channel (Bai et al., 2019).

It was also observed that the transverse slope of water surface at the apex points and cross over points of a meander bend for Froude number 0.50 is higher than that of the transverse slope of water surface with Froude number value of 0.25 . 
Table 4 shows the range of transverse slope of water surface for the numerical test cases that were run for simulation of flow.

Table 4: Change in transverse slope of water surface for different test cases.

\begin{tabular}{|c|c|c|c|c|c|c|c|}
\hline Case No. & $\begin{array}{l}\text { At apex } \\
\text { point-1 }\end{array}$ & $\begin{array}{l}\text { At apex } \\
\text { point-2 }\end{array}$ & $\begin{array}{c}\text { At apex } \\
\text { point-3 }\end{array}$ & $\begin{array}{c}\text { At cross } \\
\text { over point- } \\
1\end{array}$ & $\begin{array}{l}\text { At cross } \\
\text { over point- } \\
\quad 2\end{array}$ & $\begin{array}{l}\text { At cross } \\
\text { over point- } \\
\quad 3\end{array}$ & $\begin{array}{c}\text { At cross } \\
\text { over point- } \\
4\end{array}$ \\
\hline $\begin{array}{c}S_{1} C_{1} R_{1} \sim \\
S_{7} C_{1} R_{1}\end{array}$ & $\begin{array}{l}0.0881 \sim \\
0.00883\end{array}$ & $\begin{array}{c}0.08835 \sim \\
0.00884\end{array}$ & $\begin{array}{c}0.08856 \sim \\
0.00885\end{array}$ & $\begin{array}{c}0.0279 \sim \\
0.0028\end{array}$ & $\begin{array}{c}0.00961 \sim \\
0.00095\end{array}$ & $\begin{array}{c}0.02803 \sim \\
002795\end{array}$ & $\begin{array}{c}0.02771 \sim \\
0.00278\end{array}$ \\
\hline $\begin{array}{c}S_{1} C_{2} R_{1} \sim \\
S_{7} C_{2} R_{1}\end{array}$ & $\begin{array}{c}0.15269 \sim \\
0.01536\end{array}$ & $\begin{array}{c}0.15337 \sim \\
0.15337\end{array}$ & $\begin{array}{c}0.15394 \sim \\
0.0154\end{array}$ & $\begin{array}{c}0.04842 \sim \\
0.00485\end{array}$ & $\begin{array}{r}0.01679 \sim \\
0.00165\end{array}$ & $\begin{array}{l}0.0488 \sim \\
0.00486\end{array}$ & $\begin{array}{c}0.04804 \sim \\
0.00483\end{array}$ \\
\hline $\begin{array}{c}S_{1} C_{1} R_{2} \sim \\
S_{7} C_{1} R_{2}\end{array}$ & $\begin{array}{c}0.17873 \sim \\
0.01771\end{array}$ & $\begin{array}{c}0.17962 \sim \\
0.01776\end{array}$ & $\begin{array}{c}0.17998 \sim \\
0.01784\end{array}$ & $\begin{array}{c}0.05581 \sim \\
0.00553\end{array}$ & $\begin{array}{c}0.01921 \sim \\
0.00189\end{array}$ & $\begin{array}{c}0.05613 \sim \\
0.00556\end{array}$ & $\begin{array}{c}0.05555 \sim \\
0.00554\end{array}$ \\
\hline $\begin{array}{c}S_{1} C_{2} R_{2} \sim \\
S_{7} C_{2} R_{2}\end{array}$ & $\begin{array}{c}0.31267 \sim \\
0.03077\end{array}$ & $\begin{array}{c}0.31457 \sim \\
0.03089\end{array}$ & $\begin{array}{c}0.31494 \sim \\
0.03107\end{array}$ & $\begin{array}{c}0.09763 \sim \\
0.00957\end{array}$ & $\begin{array}{c}0.03385 \sim \\
0.00326\end{array}$ & $\begin{array}{c}0.09826 \sim \\
0.00965\end{array}$ & $\begin{array}{l}0.0966 \sim \\
0.00961\end{array}$ \\
\hline $\begin{array}{c}S_{1} C_{1} R_{3} \sim \\
S_{7} C_{1} R_{3}\end{array}$ & $\begin{array}{c}0.27699 \sim \\
0.02672\end{array}$ & $\begin{array}{c}0.27901 \sim \\
0.0269\end{array}$ & $\begin{array}{c}0.27879 \sim \\
0.02714\end{array}$ & $\begin{array}{c}0.08439 \sim \\
0.00816\end{array}$ & $\begin{array}{c}0.02903 \sim \\
0.00278\end{array}$ & $\begin{array}{c}0.08478 \sim \\
0.00825\end{array}$ & $\begin{array}{c}0.08388 \sim \\
0.00827\end{array}$ \\
\hline $\begin{array}{c}S_{1} C_{2} R_{3} \sim \\
S_{7} C_{2} R_{3}\end{array}$ & $\begin{array}{c}0.49898 \sim \\
0.04635\end{array}$ & $\begin{array}{c}0.50246 \sim \\
0.04678\end{array}$ & $\begin{array}{c}0.49752 \sim \\
0.04737\end{array}$ & $\begin{array}{c}0.15123 \sim \\
0.01406\end{array}$ & $\begin{array}{c}0.05234 \sim \\
0.00481\end{array}$ & $\begin{array}{c}0.15121 \sim \\
0.01431\end{array}$ & $\begin{array}{c}0.14703 \sim \\
0.01431\end{array}$ \\
\hline $\begin{array}{c}S_{1} C_{1} R_{4} \sim \\
S_{7} C_{1} R_{4}\end{array}$ & $\begin{array}{c}0.36906 \sim \\
0.03586\end{array}$ & $\begin{array}{c}0.39402 \sim \\
0.03631\end{array}$ & $\begin{array}{c}0.39139 \sim \\
0.03688\end{array}$ & $\begin{array}{c}0.11405 \sim \\
0.01063\end{array}$ & $\begin{array}{l}0.0392 \sim \\
0.00361\end{array}$ & $\begin{array}{c}0.11439 \sim \\
0.01082\end{array}$ & $\begin{array}{c}0.11302 \sim \\
0.01093\end{array}$ \\
\hline $\begin{array}{c}S_{1} C_{2} R_{4} \sim ~ \\
S_{7} C_{2} R_{4}\end{array}$ & $\begin{array}{c}0.72637 \sim \\
0.0619\end{array}$ & $\begin{array}{c}0.74847 \sim \\
0.06297\end{array}$ & $\begin{array}{c}0.73319 \sim \\
0.06438\end{array}$ & $\begin{array}{c}0.20847 \sim \\
0.01814\end{array}$ & $\begin{array}{c}0.07385 \sim \\
0.01866\end{array}$ & $\begin{array}{c}0.22014 \sim \\
0.01866\end{array}$ & $\begin{array}{c}0.20205 \sim \\
0.01883\end{array}$ \\
\hline
\end{tabular}

\section{CONCLUSIONS}

The flow fields of the channels with $45^{\circ}, 90^{\circ}, 135^{\circ}$ and $180^{\circ}$ bend angles with $0.15 \mathrm{~m}, 0.25 \mathrm{~m}, 0.50 \mathrm{~m}, 0.75 \mathrm{~m}, 1 \mathrm{~m}$, $1.25 \mathrm{~m}$ and $1.5 \mathrm{~m}$ channel widths were successfully simulated by using the two dimensional flow simulation software iRIC Nays2DH. The changes of transverse slope, velocity and water surface elevation due to different geometric and flow conditions of the channel were estimated by using this software. The simulation results showed that the water surface elevation at the outer bank is higher than the inner bank. From the velocity profiles, it is observed that velocity at outer bank is lower than the inner bank. It is found that, there is an increase in transverse slope of water surface due to the increase in meandering angles and Froude numbers, while it decreased with increasing channel widths having meandering length $\left(\mathrm{M}_{\mathrm{L}} / \mathrm{W}\right)$, Radius of Curvature $(\mathrm{R} / \mathrm{W})$ and Froude numbers are constant. It was also observed that the transverse slope of water surface at the apex and cross over points of a meander is higher for Froude number 0.50 than that of the transverse slope of water surface with Froude number value of 0.25 . It can be concluded that the iRIC Nays2DH software is capable for simulating the flow field at bends and as well as at straight portions.

\section{ACKNOWLEDGEMENT}

This is the extended version of the conference paper presented in ICCESD 2020. We acknowledge the two anonymous reviewers and Editor of Journal of Engineering Science for their support in the publication process. 


\section{REFERENCES}

Ahmed, M. M., Ayyoubzadeh, S.A., Namin, M. M. and Samani, J.M.V., 2009. A 2D depth averaged model for simulating and examining unsteady flow patterns in open channel bend. Department of Water Structures Engineering, College of Agriculture, Tarbiat Modares University, Tehran, Islamic Republic of Iran.

Ali, M. S., Lemon, M. H. R., and Talukder, M. A. Q., 2014. Two dimensional simulation of flows in bends of an open channel by iRIC Nays2D, Proceedings of the 2nd International Conference on Civil Engineering for Sustainable Development (ICCESD-2014), 14 16 Feb., KUET, Bangladesh.

Ali, M. S., Hasan, M.M. and Haque, M., 2017. Two-Dimensional Simulation of Flows in an Open Channel with Groin-Like Structures by iRIC Nays2DH, Mathematical Problems in Engineering, vol. 2017, Article ID 1275498, 10 pages, 2017. doi:10.1155/2017/1275498.

Ali, M. S., Hosoda, T. and Kimura, I., 2012. Unsteady RANS and LES Simulation of an Ideal Rankine Vortex Decay, Advances in Civil Engineering, Vol. 2012, Article ID 523839, 8 pages. http://dx.doi.org/10.1155/2012/523839 .

Bai, R., Zhu, D., Chen, H., Li, D., 2019. Laboratory Study of Secondary Flow in an Open Channel Bend by Using PIV, WATER, Vol. 11, no. 4: 659. https://doi.org/10.3390/w11040659.

De-Vriend, H.J. and Geoldof, H.J., 1983. Main flow velocity in Short River bends, Journal of Hydraulic Engineering, ASCE, 109: 991-1011.

Kim, T.B. and Choi, S.U., 2003. Experiment on numerical simulations of open-channel flows in a bend using the finite element method, School of Civil and Environmental Engineering, Yonsei University, Seoul, Korea.

Kimura, I., Uittewaal, W. S. J., Hosoda, T. and Ali, M. S., 2009. URANS computations of shallow grid turbulence, Journal of Hydraulic Engineering, American Society of Civil Engineering (ASCE), ISSN 0733-9429, Vol. 135, No. 2, pp. 118-131.

Leschziner, M.A. and Rodi, W., 1979. Calculation of strongly curved open channel flow, Journal of Hydraulic Engineering, ASCE, 105: 1297-1314.

Rozovskii, I.L., 1961. Flow of water in bends of open channels, Academy of Sciences of the Ukrainian SSR, Kiev, Israel Program for Scientific Translation, Jerusalem.

iRIC (2017). iRIC Software, iRIC version2.3 (32bit), available at http://iric.org/en/downloads (accessed on: June, 2017).

Shimizu, Y. and Takebayashi, H., 2014. "iRIC software Nays2DH solver manual", Nays2DH development team, Japan.

Xu, D., Ji, C., Bai, Y., Song, X., 2017. Three-dimensional numerical investigation on the influence of geometric shape on flow in river bends, Journal of Hydroinformatics, Vol. 19 (5), pp. 666-685.

(C) 2021 the Authors. Journal of Engineering Science published by Faculty of Civil Engineering, Khulna University of Engineering \& Technology. This is an open access article under the terms of the Creative Commons AttributionNonCommercial-NoDerivatives License, which permits use and distribution in any medium, provided the original work is properly cited, the use is non-commercial and no Modifications or adaptations are made. 